\section{The Earth's changing face}

Mike Kirkby

World Geomorphology. By E. M. Bridges. Cambridge University Press: 1990. Pp.260. Hbk £35, \$70; pbk £13.95, $\$ 24.95$.

Temperate Palaeohydrology: Fluvial Processes in the Temperate Zone during the last 15,000 Years. Edited by L. Starkel, K. J. Gregory and J. B. Thornes. Wiley: 1991. Pp. 548. £70, \$175.

As E. M. Bridges says in his introduction to World Geomorphology, there have been sweeping changes in understanding the Earth's crust since 1960 and some reluctance on the part of geomorphologists to digest the implications for the Earth's surface skin. Here was a perfect opportunity to provide new interpretations of major landform units, taking into account current views of plate tectonics, the great activity of the crust and our rapidly changing Pleistocene climates.

At continental scales, large-scale plate movements associated with sea-floor spreading provide passively extending continental margins like those around the Atlantic, and actively compressing margins as around the Pacific. Along passive margins, erosion and deposition lead to continental unloading and submarine loading, with consequent isostatic uplift and subsidence constrained by flexing of the elastic crust. These processes lead to the characteristic uplift of landward-dipping escarpments, increasing seaward dips in the rocks of continental coastal plains, and to the containment of catchments like the Mississippi or the Amazon which drain a large part of continental interiors. If thermal conditions in the crust are suitable it may eventually lead to progressive growth of the continent with the start of an active subduction zone.

At active margins, volcanic activity and compressive folds built mountain belts which are eroded to provide sediment which may be repeatedly recycled as it is returned to the continental margin on the subducting ocean plate. As the mountains are uplifted, their rocks are weakened by severe fracturing and the high elevations are also responsible for exceptionally high erosion rates, due to greatly increased precipitation and perhaps glaciation. Eventually the mountains become so steep and high that erosion rates balance uplift rates, perhaps even at the 20 mm per year reported for the New Zealand Alps. At smaller scales, the key interactions are between local tectonic stress fields, fault patterns and erosion, and there is much to be done before a clear understanding emerges, although some patterns may be seen, for example in block-faulted or rifted areas.

How far has Bridges achieved a worthwhile integration at the broad-scale implied by his title? Instead of a dynamic account, perhaps concentrating on those areas where most is known, we have an introductory chapter on plate tectonics at a broadly descriptive level, followed by a chapter on each of the six continents and on the Pacific Basin. For each continent, there is a token introduction on plate tectonics but rarely any dynamic view of the structure and form of the land. In fact there is very little fresh analysis and much that could have been written 50 years ago. The basic regionalization of the United States, for example, where much is now known, is still based on N. M. Fenneman's analysis of the 1930s and there is nothing on the dynamic behaviour of the mountain masses of the California coast.

Of course there are difficulties in attempting a region-by-region account of landforms across the world, but the resulting book frequently declines to the level of a catalogue of areas, with no space to give more than a bare description of each, and certainly no chance to present or discuss new insights. I hope that another author will take up the challenge.

Temperate Palaeohydrology edited by L. Starkel, K. J. Gregory and J. B. Thornes might appear to have a similar sweep in scope, with its 15,000-year time span, but its aims are more modest in scope. It is the concluding volume in a series of edited contributions arising from a project undertaken by the Internation Geological Correlation Programme over the last decade. The theme is introduced by chapters on river hydrology and the sedimentology of river deposits. Over half of the book consists of a series or regionally based case studies which span
Europe. There are three studies on Britain, two each on Finland, Benelux, Poland and the Danube basin, and one each on the eastern Baltic, Switzerland and western Siberia. In all cases the crucial evidence relates to dating and correlation of buried channels and terraces with other forms of evidence for changes in relative sea levels and erosion rates. Several of the studies are for areas of glacial isostatic rebound. Another group is for areas influenced by glacial meltwater or ice damming, and there is a group of rivers which were not directly influenced by glaciation.

The final 150 pages of the book provides some broader perspectives. The most substantial is a survey of methods for retrodicting former discharges from the sedimentological record, with the implications for the associated hydrological balances for the immediately postglacial period, when discharges were several times greater than today. The changes are attributed mainly to the lower evapotranspiration in cooler conditions rather than to major changes in precipitation. There are also useful perspectives on glacier fluctuations, and on the possibilities for broad correlations across the whole area of Europe, among others. Like many other contributed collections, Temperate Palaeohydrology gives a fair view of the state of the art in a particular field, but emphasizes the diversity of activity rather than providing broad insights which could be carried back to the global scale attempted in World Geomorphology.

Mike Kirkby is in the School of Geography, University of Leeds, Leeds LS2 9JT, UK.

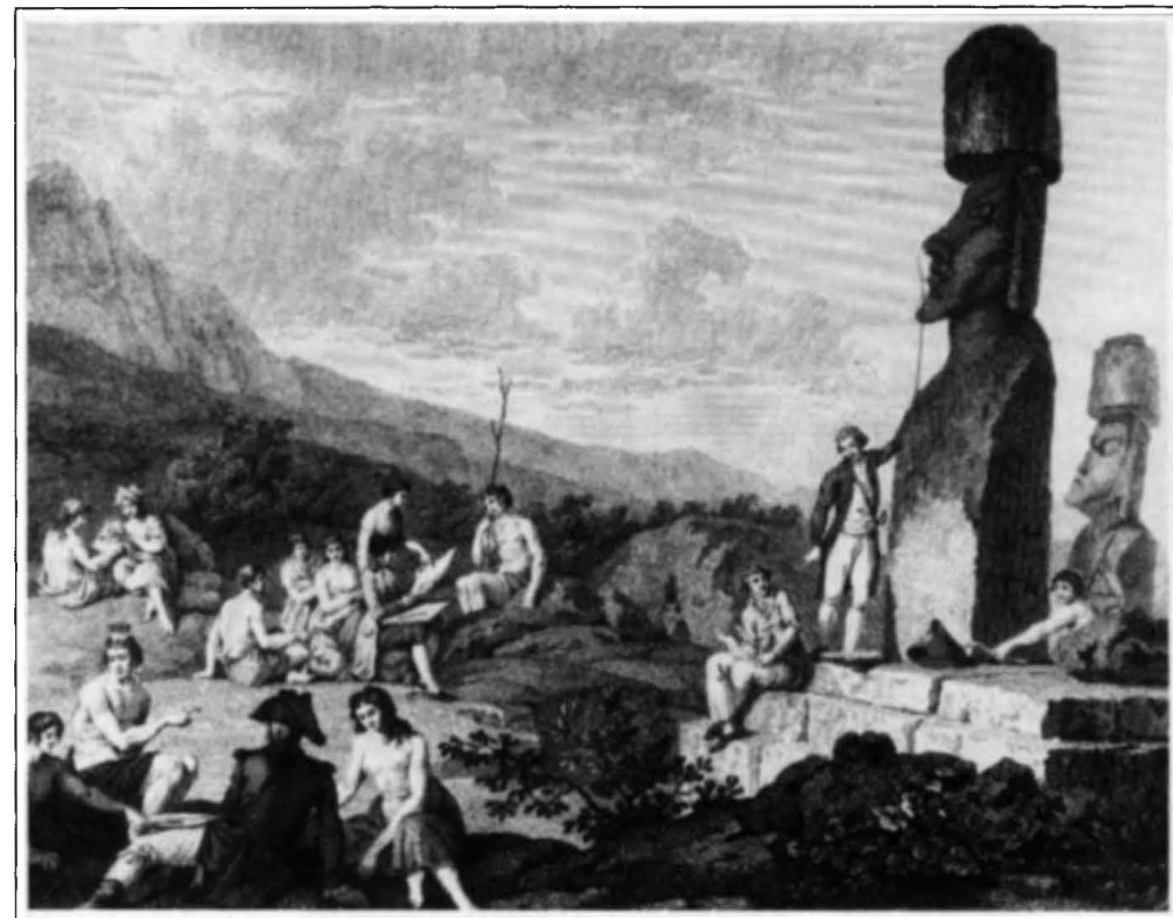

Pacific paradise - Dutchman Jacob Roggeveen discovered Easter Island in 1721 when the famous stone figures still had the headpieces intact. The island's people apparently believed their nearest neighbours were on the Moon. Taken from The Royal Geographical Society History of World Exploration edited by John Keay (Hamlyn, $\$ 20, \$ 29.98$ ). 